\title{
The Roles of Product Attributes towards Generation-Y Shopping Interest
}

\author{
Abd Majid Nurul Fazura ${ }^{1}$, Musa Haslinda ${ }^{1}$, Hasan Hazmilah $^{2}$, Othman Norfaridatul Akmaliah ${ }^{1}$, Azmi Fadhlur Rahim ${ }^{1}$ \\ ${ }^{1}$ Faculty of Technology Management and Technopreneurship, Universiti Teknikal Malaysia Melaka, 76100 Durian Tunggal Melaka, \\ Malaysia \\ ${ }^{2}$ Centre of Technopreneurship Development (C-TeD), Universiti Teknikal Malaysia Melaka, 76100 Durian Tunggal Melaka, Malaysia
}

\begin{abstract}
Generation Y is the second largest generational cohort growing up in a world infused with brands that has been socialized in a materialistic society with purchasing power and extraordinary impact on the economy. They often involve with the shopping behavior and purchase involvement that makes their preferences towards one product would most likely depending on the attributes of the product itself. Thus, this study has developed a framework that explored the generation- $Y$ shopping interest towards product attributes. This study applied four (4) concepts; which are the functions of the product, features of the product, benefits of the product, and generation-Y shopping interest. In this study, the researcher used empirical study by employing the questionnaire survey to investigate its managerial implications to 150 respondents of generation-Y. The data collected is analyzed by using Statistical Package for Social Science (SPSS) that showed all features of the product, functions of the product, and benefits of the product are positively affected the generation-Y shopping interest.
\end{abstract}

\section{Introduction}

Generation Y has to be those who born between 1978 and 1994 that born straightaway after Generation X, and it is referred to the dot.com generation, eco boomers and millionaires [1,2]. Generation Y often involve with the shopping behaviour and purchase involvement for books, apparel, and electronics such as clothing, computers, CDs, and electronics [3]. It has been socialized that the purchasing power of Generation $\mathrm{Y}$ has an extraordinary impact on the economy and this generational cohort is highly active in the marketplace [4] which is also held true in the Malaysian context and makes up the largest segment of Malaysia's population $[1,5]$. Generational cohorts have different values, preferences and shopping behaviours but they have emerged as a big force with growing spending power which will unsurprisingly competing to other cohorts [58]. Furthermore, Generation $\mathrm{Y}$ which is so called Millennial, is a specific cohort who usually have similar characteristics and features that can be found in many fields of interest, e.g. lifestyle, choice of education or job and also in shopping behaviour [4]. They see themselves as special and enjoy activities such as listening to music, watching television, going to the movies, and eating out.

However, their preference towards one product is not fixing depending on the attributes of the product itself. For example, if there is slight of the Generation Y does not like to read and comprehend dull textual information through books because the features of the text is not interesting, they will go for the electronic platforms as they found that the functions of the electronic gadgets is more stimulating and dynamic [10]. This assumption can be completely applied especially for one group of Generation $\mathrm{Y}$ which consists of mostly visual learners. Holistically, the product is evaluated for its fit with the desired benefits that not relied on a feature-by-feature comparison of alternative brands, but by the consumer choice that make consumers selectively attend to product features based upon the benefits sought [11].

\section{Methodologies}

For this research, the researcher used quantitative data analysis to examine relationships between variables which will be measured numerically and analysed using a range of statistical techniques. On this research, the data is measured on a numerical that has been specified by using statistical techniques and the result can be shown using charts, histograms, tables and graphs [12].

The researcher used primary data in this research. The primary data for this research is collected by using questionnaires. One set of questions is designed and distributed to 150 respondents and focus on generation $\mathrm{Y}$ in Melaka area. The questionnaires are based on this research topic. The questionnaire has been constructed carefully so that the information collected is valid. Secondary data sources such as books and journals are the subsequent publication of primary data sources. These publications are aimed at a wider audience. They

\footnotetext{
* Corresponding author: haslindamusa@utem.edu.my
} 
are easier to locate than primary data sources as they are better covered by the tertiary data sources.

\section{Results and Discussion}

\subsection{Respondents' Demographic Profile}

The results obtained from 150 respondents are presented in Table 1. It shows summary of the respondent's background and characteristics. From 150 respondents, $34.7 \%$ are male, and $65.3 \%$ are female. In terms of percentage of qualification, $56 \%$ of the respondents own bachelor degree, followed by $30 \%$ of Diploma and $9.3 \%$ own Master \& above. Lastly, $4.70 \%$ own SPM. Respondent within the age of 22-25 years old with value $49 \%$ as a majority of the respondents which is 74 people over 150 respondents in this result. This is followed by $28.0 \%$ of respondents (42 people) among 26-30 years old. Furthermore, $18.0 \%$ of respondents (27 people) are 31-34 years old. Last but not least, only $4.7 \%$ of respondents (7 people) in range of age 35-39 years old. Percentage of races between respondents who participated in this survey. $83 \%$ of the respondents are Malay, $10 \%$ are Chinese, and $7 \%$ are Indian. Malays has dominated this survey questionnaire for the research purpose. Employment status shows the highest percentage is students that are $49.30 \%$ which represent 74 numbers of respondents. The second highest of respondents' employment status is $21.30 \%$ which represents 32 number of respondents from private sector. This followed by $15.30 \%$ from government sector that indicates 32 respondents. The lowest is $14.00 \%$ of respondents who are self-employed which represents 21 numbers of respondents. The researcher can induce that most of the participants of the survey are students followed by private sector, government sector and selfemployed. Based on the table 1, it shows the monthly income or allowance of the 150 respondents where $47.30 \%$ of them have the income that less than RM1000. The second is $27.30 \%$ for the income range of RM1001RM2000 with 41 respondents and 26 respondents that is $17.30 \%$ from 150 respondents have the income of RM2001-RM3000. As most of the respondents are students, then most of the respondents' monthly income or allowance is below than RM1000.

Table 1. Respondents' demographic profile

\begin{tabular}{|c|c|c|}
\hline & Frequency & Percent \\
\hline Gender & $\mathbf{1 5 0}$ & $\mathbf{1 0 0 . 0}$ \\
\hline Male & 52 & 34.7 \\
\hline Female & 98 & 65.3 \\
\hline Age & $\mathbf{1 5 0}$ & $\mathbf{1 0 0 . 0}$ \\
\hline $22-25$ & 74 & 49.3 \\
\hline
\end{tabular}

\begin{tabular}{|c|c|c|}
\hline $26-30$ & 42 & 28.0 \\
\hline $31-34$ & 27 & 18.0 \\
\hline $35-39$ & 7 & 4.7 \\
\hline Qualifications & 150 & 100.0 \\
\hline SPM & 7 & 4.7 \\
\hline Diploma & 45 & 30.0 \\
\hline Degree & 84 & 56.0 \\
\hline Master and others & 14 & 9.3 \\
\hline Race & 150 & 100.0 \\
\hline Malay & 125 & 83.3 \\
\hline Chinese & 15 & 10.0 \\
\hline Indian & 10 & 6.7 \\
\hline Occupations & 120 & 100.0 \\
\hline Government sectors & 23 & 15.3 \\
\hline Private sectors & 32 & 21.3 \\
\hline Self-employed & 21 & 14.0 \\
\hline Student & 74 & 49.3 \\
\hline $\begin{array}{l}\text { Monthly Income or } \\
\text { Allowance (RM) }\end{array}$ & 150 & 100.0 \\
\hline Less than 1000 & 71 & 47.3 \\
\hline $1001-2000$ & 41 & 27.3 \\
\hline $2001-3000$ & 26 & 17.3 \\
\hline 3001 and above & 12 & 8.0 \\
\hline
\end{tabular}

\subsection{Pearson's Correlation Analysis}

Table 2. Pearson Correlation between the variable

\begin{tabular}{|c|c|c|c|c|}
\hline & 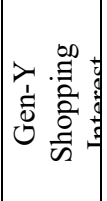 & 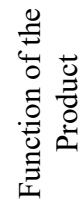 & 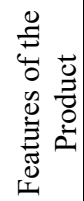 & 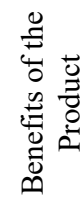 \\
\hline 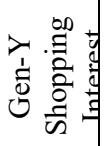 & . & & & \\
\hline
\end{tabular}




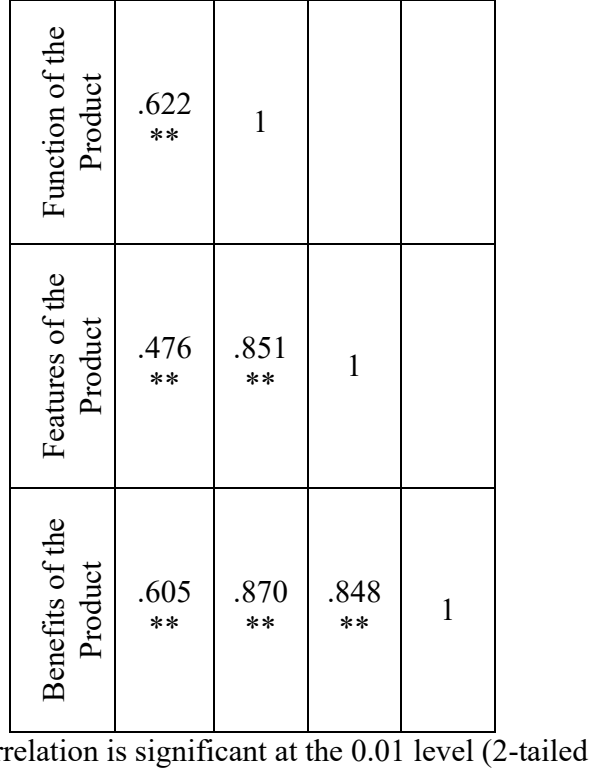

Table 2 shows correlation between independent variables (functions of the product, features of the product, and benefits of the product) with dependent variable (gen-y shopping interest). There is moderate relationship between functions of the product and gen-y shopping interest. The value of the coefficient correlation is 0.622 , falls under the coefficient range of " \pm 0.41 to \pm 0.70 ". There is moderate relationship between features of the products and gen-y shopping interest. The value of the coefficient correlation is 0.476 , falls under the coefficient range of " \pm 0.41 to \pm 0.70 ". Last but not least, there is moderate relationship between benefits of the products and gen-y shopping interest. The value of the coefficient correlation is 0.605 , falls under the coefficient range of " \pm 0.41 to \pm 0.70 ".

Table 3 shows Multiple Regression Analysis (MRA), $\mathrm{R}$ is 0.658 which is more than 0.5 that indicates positive relationship. This means that the respondent is good on shopping and product attributes. Furthermore, the positive sign of $\mathrm{R}$ implies a positive relationship. Coefficient of determination, $\mathrm{R}^{2}$, is the proportion of variance in one variable associated with the variability in a second variable. From the result, it shows that $43.30 \%$ of the variables affected the gen-y shopping interest and that means $56.70 \%$ indirect factor other than variable that has been used for this study influenced the gen-y shopping interest.

Table 3. Multi Regression Analysis

\begin{tabular}{|c|c|c|c|c|c|}
\hline Model & $\mathbf{R}$ & $\mathbf{R}^{2}$ & $\begin{array}{c}\text { Adjuste } \\
\mathbf{d ~ R}^{2}\end{array}$ & $\begin{array}{c}\text { Std. } \\
\text { Error of } \\
\text { the } \\
\text { Estimate }\end{array}$ & Sig. \\
\hline 1 & 0.658 & 0.433 & 0.421 & 0.596 & 0.00 \\
\hline
\end{tabular}

Based on Table 3, it shows the percentage of relationship between variables and the significant of each of variables that affect gen-y shopping interest. The first factor, functions of the product is significant to the gen-y shopping interest as its value amounted 0.000 and it is below than 0.005. The second factor which is features of the product is significant with the value of 0.007 and below than 0.05 . Lastly, the last factor which is benefits of the product is also significant to the gen-y shopping interest as its value is 0.003 which is below than 0.05 . The relationship can be denoted as the following equation from the analysis from the Table 4 below:

\section{$Y$ Gen-Y Shopping Interest $=1.272+0.575$ Functions of the Product -0.379 Features of the Product +0.430 Benefits of the Product}

According to Table 4, functions of the product have positive influence on gen-y shopping interest $(\mathrm{t}=4.002$, $p=0.000, \beta=-0.575)$. When other variables are held constant, every one unit increase in functions of the product will lead to increase in gen-y shopping interest by 0.575 units. From the analysis in table 4 , it shows that features of the product have negative influence on the gen-y shopping interest $(\mathrm{t}=-2.737, \mathrm{p}=0.007, \beta=0.379)$. It can be explained by every one unit increase in features of the product will lead to 0.379 units decreased in gen-y shopping interest. Table 4.19 also shows that benefits of the product was found to exert a significant positive influence on gen-y shopping interest $(\mathrm{t}=3.017, \mathrm{p}=0.003$, $\beta=0.430$ ). It can be explained by every one unit increase in benefits of the product will lead to 0.430 units increased in gen-y shopping interest. It can be concluded the functions of the product is the factor that contributes the most to the gen-y shopping interest. The value of functions of the product that influences gen-y shopping interest is 0.575 which is $57.50 \%$ and it is the highest value compared to the other two variables.

Table 4. Multi Regression Analysis

\begin{tabular}{|c|c|c|c|c|c|}
\hline \multirow{2}{*}{ Model } & \multicolumn{2}{|c|}{$\begin{array}{c}\text { Unstandardized } \\
\text { Coefficients }\end{array}$} & \multirow[b]{2}{*}{ Beta } & \multirow{2}{*}{$t$} & \multirow{2}{*}{ Sig. } \\
\hline & B & $\begin{array}{c}\text { Std. } \\
\text { Error }\end{array}$ & & & \\
\hline 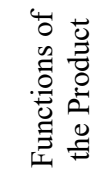 & 0.575 & 0.144 & 0.561 & 4.002 & 0.000 \\
\hline 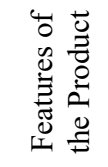 & -0.379 & 0.139 & -0.357 & -2.737 & 0.007 \\
\hline 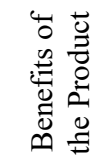 & 0.430 & 0.142 & 0.420 & 3.017 & 0.003 \\
\hline 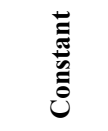 & 1.272 & 0.281 & & 4.527 & 0.00 \\
\hline
\end{tabular}




\section{Conclusion}

Research objectives are achieved and proved that the product attributes; features, functions, and benefits of the product are factors that significantly enhanced generation Y shopping interest.

\section{References}

1. M. Muda, R. Mohd, and S. Hassan, "Online Purchase Behavior of Generation $\mathrm{Y}$ in Malaysia," Procedia Econ. Financ., vol. 37, pp. 292-298, 2016.

2. P. Kotler and G. Armstrong, Principles of marketing. Pearson education, 2010.

3. T. R. Kinley, B. M. Josiam, and F. Lockett, "Shopping behavior and the involvement construct," J. Fash. Mark. Manag. An Int. J., vol. 14, no. 4, pp. 562-575, Sep. 2010.

4. P. Krbová, "Generation Y attitudes towards shopping: a comparison of the Czech Republic and Slovakia," J. Compet., vol. 8, no. 1, 2016.

5. H. Musa, M. S. M. Taib, S. C. H. Li, J. Jabar, and F. A. Khalid, "Drop-sshipping supply chain: the characteristcs of SMEs towards adopting it," Soc. Sci., vol. 11, no. 11, pp. 2856-2863, 2016.

6. H. Musa, S. C. H. Li, Z. A. Abas, and N. Mohamad, "Adoption Factor of Mobile Marketing: The Case of Small Medium Enterprises (SMEs) in Malaysia," Int. Rev. Manag. Mark., vol. 6, no. 7S, pp. 112-115, 2016.

7. H. Musa, N. A. Rahim, F. R. Azmi, A. S. Shibghatullah, and N. A. Othman, "Social Media Marketing and Online Small and Medium Enterprises Performance: Perspective of Malaysian Small and Medium Enterprises," Int. Rev. Manag. Mark., vol. 6, no. 7S, pp. 1-5, 2016.

8. T. J. Fogarty, A. Reinstein, and R. S. Heath, “Are Today's Young Accountants Different? An Intergenerational Comparison of Three Psychological Attributes," Account. Horizons, vol. 31, no. 2, pp. 83-104, Jun. 2017.

9. A. Bilgihan, "Gen Y customer loyalty in online shopping: An integrated model of trust, user experience and branding," Comput. Human Behav., vol. 61, pp. 103-113, Aug. 2016.

10. H. Musa, "Analyzing factors towards adopting ICT within supply network in the UK, " $J$. Technol. Manag. Technopreneursh., vol. 2, no. 1, pp. 19-35, 2014.

11. A. Ponnam and J. Dawra, "Discerning product benefits through visual thematic analysis," $J$. Prod. Brand Manag., vol. 22, no. 1, pp. 30-39, Feb. 2013.

12. M. Saunders, Research methods for business students, 5/e, 5th ed. Pearson Education India, 